\title{
Helping Learners Develop Interactional Competence Through Project Work in the Language Classroom
}

\author{
Nicholas Marshall \\ Meiji University, Tokyo, Japan
}

\begin{abstract}
The acquisition of interaction itself, rather than language in its formal properties (or talk, in a monological sense) is captured by the term interactional competence (IC). This has a bedrock status in human sociality in general, but is often ironically difficult to achieve in foreign language classrooms. This paper proposes that elements of project work involving interactive and collaborative activity, where goals must be negotiated in small groups, are effective in developing learners' IC. A central concept here is procedural negotiation, where learners need to agree on how to proceed on an ongoing basis. Strong versions of this approach, where it is a key component of the curriculum, may not always be feasible or even appropriate, especially in traditional Asian contexts, but can be adopted to lesser or greater degrees. Suggestions are made about how to structure this kind of learning, and one unit of work is discussed.
\end{abstract}

This paper proposes a set of teaching practices and also guidelines for a sample unit of work, for the purpose of developing a basic interactional competence (IC) in English as a foreign language for students of high school or college level. This is especially applicable in situations, as in much of Asia, where learners are often not exposed to naturally-occurring contexts of interaction in English outside of classrooms. Making such generalizations may seem at first glance to be overly simplistic since the term Asia encompasses the bulk of the world's population and the tremendous diversity between nation states as well as great internal variation within national boundaries. However, if classroom learning is modeled as a set of institutional practices (Young, 2009) with a focus on the conventions of learner and teacher roles and the ways that these shape the possibilities of both learner and teacher talk, there can be remarkable similarities across cultures (Bernstein, 1996). Thus, in this way, general observations do have considerable validity.

\section{Literature Review}

In large classes where the main goal is formal instruction in the phonology, lexis, and grammar of the foreign language, the usual way of achieving this goal is through transmission models of education (Wells, 1999). Typically, this means that a body of skills and information is delivered to a group of passive students, who hopefully develop declarative knowledge, i.e., knowing that something is so, rather than how to do something, regarding the subject being studied

Language Education in Asia, 2012, 3(2), 168-175. http://dx.doi.org/10.5746/LEiA/12/V3/I2/A05/Marshall 
(Anderson, 1976). This traditional kind of education is very useful for managing classes with large numbers of students. In addition, in cases where learners are evaluated through their understanding of language as a system in terms of grammar and translation, the approach can be highly effective.

However, if some degree of learning to interact in the foreign language is to be introduced-and this might be only rudimentary-a different approach is needed. In this case, "what is learned is not the language, but the practice" (Young, 2007, p. 251). In other words, the focus is not knowledge about the foreign language itself, but changes in the type of activity or experience of participation in interaction with others in joint activity mediated by the target language. This IC (Hall \& Doehler, 2011) implies the mutual coordination of action by interactants through turntaking, organization, initiation and change of topic using general lexical and grammatical resources, intonation, and non-verbal resources such as body language and eye contact. Trying to engage students accustomed to classroom cultures of teacher centeredness to engage in this kind of activity can be daunting, both from the perspective of devising suitable activities and materials and from having to justify the approach to students. However the important point is that this kind of learning is aimed at socializing students into interaction, and it aims at a proactive identity. It is the start of a process that could extend over several years or even decades. Generally, it is suited to learners who have enough linguistic resources to interact at an elementary level in English. For those who do not yet have the necessary proficiency for basic interaction, the approach is likely to produce only frustration.

The following section exemplifies one approach to developing the kind of interactional behavior described above (Hall \& Doehler, 2011), using elements of simple projects (symbols used for the transcription data are shown in Appendix A). In very broad terms, project-based learning in English language education is underpinned by constructivist notions of self-direction, collaboration, reflective learning, and dialogical learning, with personalized meaning-making at its core. However, from the perspective of the development of IC on behalf of learners, FriedBooth's (2002) first stage of project work, which concerns planning, is especially relevant. In Fried-Booth's account, teachers and students discuss what needs to be done together (although, in the data following, the teacher is absent from the dialogue). Here, the important point is that the dilemma about what to do and how to proceed is resolved through peer interaction, without a teacher; the problem solving consists of several cumulative micro-stages leading towards a concrete plan. Overall, the planning stage is best thought of as a series of "maxitasks" (Nunan, 2004, p. 133) that lead to a final product.

According to Mori (2002), the instructional design of tasks for classroom learning generates particular formats of interaction. In the case following, the principle is that learners in small groups have to negotiate among themselves the content of some kind of small project that they will present together to the class at a later date. The task is convergent in nature, in that before they prepare for their presentation, they have to agree on a plan that they will explain to the teacher. There is also a time limit which creates pressure for an agreed outcome, and it is the need to arrive at a concrete plan that drives the interaction forward. However, the important point is that learners, together, must solve several micro-problems and reach agreement about how to proceed on an incremental basis. Breen and Littlejohn (2000, p. 8) term this procedural negotiation; it is intrinsic to the IC discussed earlier. 


\section{Preparing for Interaction}

\section{Methodology}

The planning for projects, the subject of this paper, was originally the main part of an expanded theme-based cycle in an innovative syllabus which was intended to engage learners in extended peer interaction across a range of activity and discourse types (Marshall, 2003). Table 1 shows the stages. Each stage is organized around a single theme of work (e.g., living overseas, travel and tourism). Several themes of work were repeated across one academic year. To give a sense of pacing and time, each individual theme took up about six class hours per week, continuing for about three weeks each.

Table 1

\section{Prototypical Cycle of Activities}

\begin{tabular}{|c|c|c|}
\hline Stage & Activity & Value \\
\hline 1. Content & $\begin{array}{l}\text { Building lexis and schema of a theme } \\
\text { Collaborative re-construction of listening } \\
\text { text through dictogloss activity }\end{array}$ & $\begin{array}{l}\text { Receptive skills, basis for } \\
\text { following stages } \\
\text { Analytical }\end{array}$ \\
\hline 2. Process & $\begin{array}{l}\text { Negotiation / planning of presentation } \\
\text { content, roles and activities of small } \\
\text { group ( } 3 \text { persons) members }\end{array}$ & $\begin{array}{l}\text { Dialogical-interactional } \\
\text { Experiential / constructivist }\end{array}$ \\
\hline $\begin{array}{l}\text { 3. Public } \\
\text { performance to } \\
\text { peers }\end{array}$ & $\begin{array}{l}\text { Group presentation } \\
\text { Extended talk addressed to whole class } \\
\text { Concern with accuracy and fluency }\end{array}$ & $\begin{array}{l}\text { Monological-interactional } \\
\text { Public "product" of group } \\
\text { work }\end{array}$ \\
\hline $\begin{array}{l}\text { 4. Self-assessment } \\
\text { with peers, } \\
\text { reflection }\end{array}$ & $\begin{array}{l}\text { Evaluation of performance of self and } \\
\text { group with peers } \\
\text { Discussion of goals and learning } \\
\text { strategies }\end{array}$ & $\begin{array}{l}\text { Dialogical-interactional } \\
\text { Self awareness, responsibility } \\
\text { for own learning }\end{array}$ \\
\hline
\end{tabular}

The goal of this innovative syllabus was to prepare first-year English majors at a private university in Japan, who were mostly interactive novices, for active participation in subsequent English classes and seminars in English. This was intended as a transition from their prior learning experiences in high school, which consisted mostly of preparing for rigorous tests in receptive skills and knowledge of rules of usage in English. The heart of the syllabus was Stage 2 , the process stage, in Table 1 . It was at this stage that learners in small groups (three people) had to decide on the content and each member's role for a collaborative presentation connected with a particular theme (e.g., overseas travel). It was felt that this would be the best way to engender the kind of interactional competence described earlier.

For this peer interaction to succeed, it is advisable to pre-teach and check understanding of some functional phrases that are useful when negotiating elements of a collaborative project. The following activity can be useful, moving from learner awareness to production. Following from the assertion in the lexical approach that language consists of not only generative items in the sense of lexis and grammar, but also collocated chunks of words (Lewis, 1993; Willis, 1990), it can also be helpful to learners to be drilled in items such those in Figure 1, so that these phrases can be used almost automatically in later group work. 
Rank the following phrases in order from weakest to strongest: I think we should ... We could do ... How about if we do... Why don't we... Let's do... Do you think we could ...?

Figure 1. Lexical expressions for negotiating content of projects for presentation.

\section{Interaction}

In the transcript excerpt shown in Figure 2, the learners are working together in class to decide what content to present about the experience of living overseas (for Japanese people). They have previously completed units of work on reading and also a dictogloss connected with the theme of living overseas in general (Stage 1 in Table 1), and now must apply the vocabulary and schemata in preparing their presentation. Similar to other small groups of learners in the class, the three young adults in the transcript are putting together their ideas. They have seventy minutes to devise a plan of action that they will later explain to the teacher, who will either approve it or make suggestions for changes.

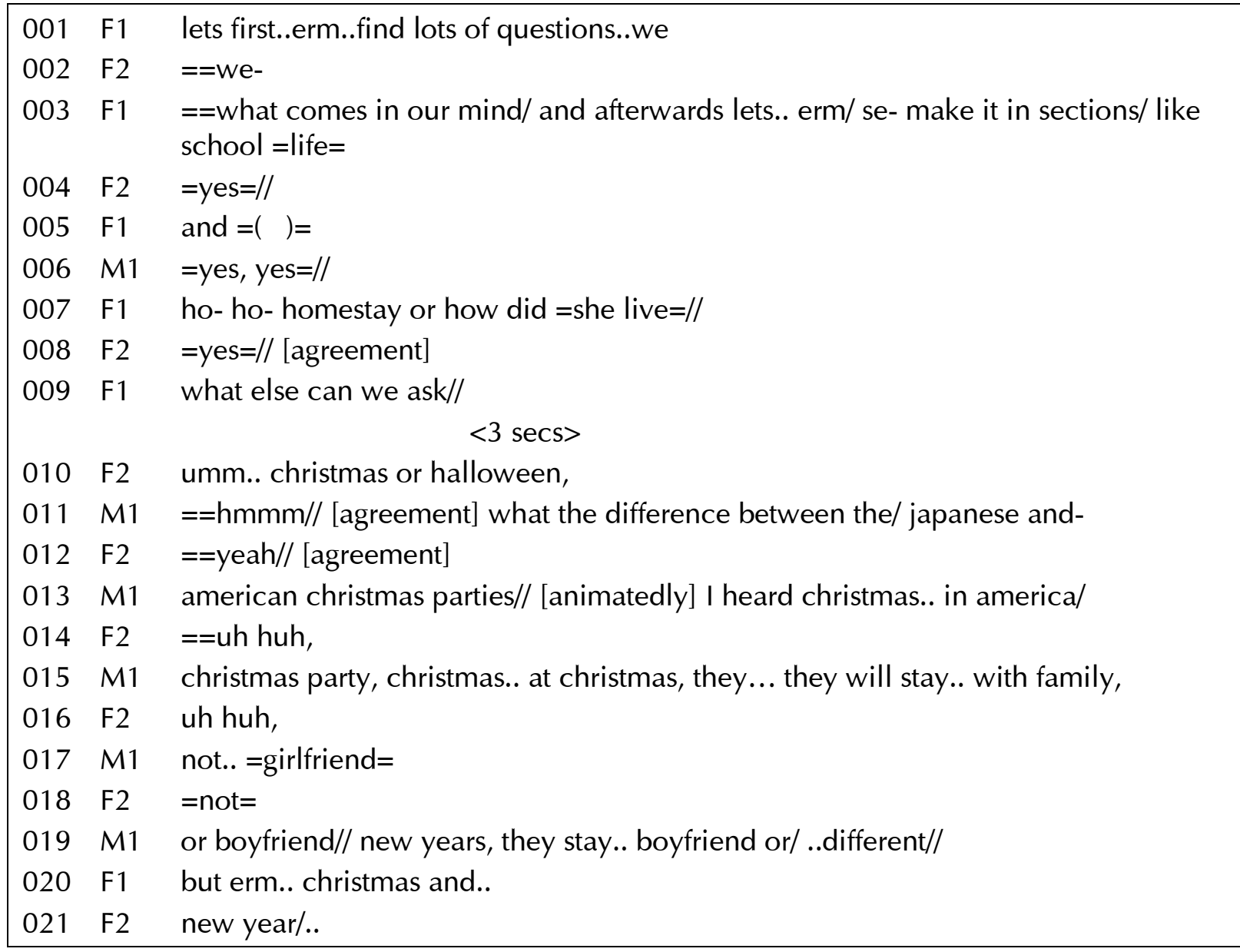

Figure 2. Excerpt from transcript of student interaction 
The complete transcript is very long and is not shown here for reasons of space. Instead, one short segment is used to demonstrate the three young learners engaged in the process of acquiring interactional competence in the target language, English. The three teenage students, two female (F1 and F2) and one male (M1), are sitting on chairs arranged in a circle. With notepaper, they are deciding on questions to use in an interview with one of their peers who has lived for a period of time in the United States. After interviewing their friend in English about her experience of living outside of Japan, they will use her responses for a presentation about Japanese people who have lived abroad. F2 and M1 have just concluded an off-task joking exchange and in Line 001, F1 takes an initiating role by bringing the other two back to the activity at hand, collaboratively formulating suitable questions for the interview. The demands of the activity are perhaps more complex than might be apparent at first glance as there needs to be some kind of shared understanding about how exactly they should proceed. F1 proposes (001) that they first come up with a list of questions, as in brainstorming, and then analyze these into sections. She gives examples of categories to clarify her point $(003,007)$.

Although $\mathrm{F} 1$ is prominent in the exchange, the talk is collaborative. The latching in 002 shows that F2 is attempting to take the floor; she subsequently interjects with overlapping speech in 004 and 008 to show her agreement, as does M1 in 006. F1 then sets up the next topic in 009 as she solicits suggestions for more questions and hands over the floor. With rising intonation suggesting tentativeness, F2 proposes Christmas or Halloween as topics for questions (010); these are both celebrated in Japan, but with some slight differences compared with North America or other Western societies. M1 picks up on the idea of focusing on these differences in 011 , which is supported by F2 in 012 . He then enthusiastically elaborates in 013, while F2 demonstrates attention in 014. M1 explains, within the limits of his proficiency, that Christmas tends to be a family event in the U.S.A. $(015,017)$, which he finds interesting, as this is often seen as a significant dating day for young Japanese. F2 shadows his utterances to signal engagement in 018. M1 concludes this idea in 019 and then begins to explain that New Year's Eve in the United States is often a significant evening for young people to date (while in Japan it is generally a family event). In 020, F1 enters the discussion after being quiet for several turns, but stalls, presumably to give herself time to process what she intends to say. Demonstrating engagement and alignment, F2 completes F1's utterance in 021. Following the segment shown, the students fall silent for several seconds as they ponder how to continue; they then raise several other topics which could become the subject of questions for their interviewee.

\section{Discussion}

A quick glance at the data above shows short utterances with simplified grammar, and the overall impression may be that the interaction is not at all sophisticated and therefore of dubious value. However, the learners are formulating a plan and the context of the talk is developing online through sequential turns. They are collaboratively working towards a list of questions for the student who they intend to interview, and they are engaged in mutual attention as they solve the problem about exactly what to do and how to proceed. It is the functional need for procedural negotiation that drives the interaction forward. Ideas for interview questions are put forward and accepted and across the turns in the transcript, the intersubjective construction of meaning and the subjective reinterpretation of utterances that reflect IC can be seen.

Despite the relatively short length and syntactic simplicity of the utterances, the transcript shows a high degree of inter-activity and participation in the joint activity. The overlapping and frequent latching of turns demonstrates competition for the floor in the first case and a high degree of reactivity to a prior utterance in the second case. In sum, this data amounts to evidence of active participation in mutual coordination of the developing context of the talk. 
Another interesting point is that, although this is a language classroom, in the transcript excerpt, there is no evidence of teacher talk. Indeed, in the complete transcript, the teacher only briefly comes over to the group once to ask if there are any problems. This point is not trivial. A defining point of classroom discourse is that teachers will tend to dominate talk within the room through regulative discourse (i.e., management, consisting largely of directives and instructional discourse) that is usually concerned with explanation (Christie, 2002). Removing the teacher from the interaction means that learners must initiate, develop, and switch topics themselves, without adopting the subject position of more conventional classroom roles. Put simply, if the teacher is assigned to a marginal role, the learners assume prominence in interaction - the exercise of IC.

\section{Conclusion}

The kind of approach described here aims at the acquisition of interaction, IC specifically, rather than language itself. The main focus is on socialization to engage in collaborative problem-solving activities with others by using learners' existing linguistic resources. The extent to which the kind of project work described above is feasible in different settings of English language education in Asia or elsewhere will vary greatly according to local contexts; important factors include consideration of student needs and support from institutional management. The approach can be adopted, either as a key component of an English curriculum (strong approach), or on an occasional or added-on basis (weak approach). Situations where classes are smaller, possibly classes where English is an elective subject and learners are more motivated, are especially suited to more experiential modes of learning. This kind of activity may also be successful in the English clubs and circles that exist in many high schools and colleges in Japan and other countries in Asia.

In conclusion, the introductory overview presented here is an example of a post-method approach that will be useful and viable in some contexts and less so in others. The outline described is very brief, but in the hands of creative and capable teachers, different variations of this approach can be successfully applied to a range of teaching and learning situations where the primary goal is to engage learners in situations of extended interaction with clear goals.

\section{Author Note}

Nicholas Marshall, Graduate School, Meiji University, Tokyo, Japan.

Correspondence concerning this article should be addressed to Nicholas Marshall at nmarshall@gol.com 


\section{References}

Anderson, J. R. (1976). Language, memory, and thought. Hillsdale, NJ: Erlbaum.

Bernstein, B. (1996). Pedagogy, symbolic control and identity: Theory, research, critique. London, England: Taylor \& Francis.

Breen, M. P., \& Littlejohn, A. (Eds.). (2000). Classroom decision-making: Negotiation and process syllabuses in practice. Cambridge, England: Cambridge University Press.

Christie, F. (2002). Classroom discourse analysis: A functional perspective. London, England: Continuum.

Fried-Booth, D. L. (2002). Project work. Oxford, England: Oxford University Press.

Gumperz, J. (1992). Contextualization and understanding. In A. Duranti \& C. Goodwin (Eds.), Rethinking context: Language as an interactive phenomenon (pp. 229-252). Cambridge, England: Cambridge University Press.

Hall, J. K., \& Doehler, S. P. (2011). L2 interactional competence and development. In J. K. Hall, J. Hellerman, \& S. P. Doehler (Eds.), L2 interactional competence and development (pp. 1-15). Bristol, England: Multilingual Matters.

Lewis, M. (1993). The lexical approach: The state of ELT and a way forward. Hove, England: Language Teaching Publications.

Marshall, N. (2003). Framing the discourse: Co-construction and peer interaction in the foreign language curriculum (Unpublished PhD thesis). Macquarie University, Sydney, Australia.

Mori, J. (2002). Task-design, plan, and development of talk-in-interaction: An analysis of a small group activity in a Japanese language classroom. Applied Linguistics, 23(3), 323-347. http://dx.doi.org/10.1093/applin/23.3.323

Nunan, D. (2004). Task-based language teaching. Cambridge, England: Cambridge University Press.

Wells, G. (1999). Dialogic inquiry: Toward a sociocultural practice and theory of education. New York, NY: Cambridge University Press.

Willis, D. (1990). The lexical syllabus: A new approach to language teaching. London, England: Collins.

Young, R. F. (2007). Language learning and teaching as discursive practice. In Zhu Hua, P. Seedhouse, Li Wei, \& V. Cook (Eds.), Language learning and teaching as social interaction (pp. 251-271). New York, NY: Palgrave Macmillan.

Young, R. F. (2009). Discursive practice in language learning and teaching. Malden, MA: Wiley-Blackwell. 


\section{Appendix \\ Transcription Scheme}

(adapted from Gumperz, 1992)

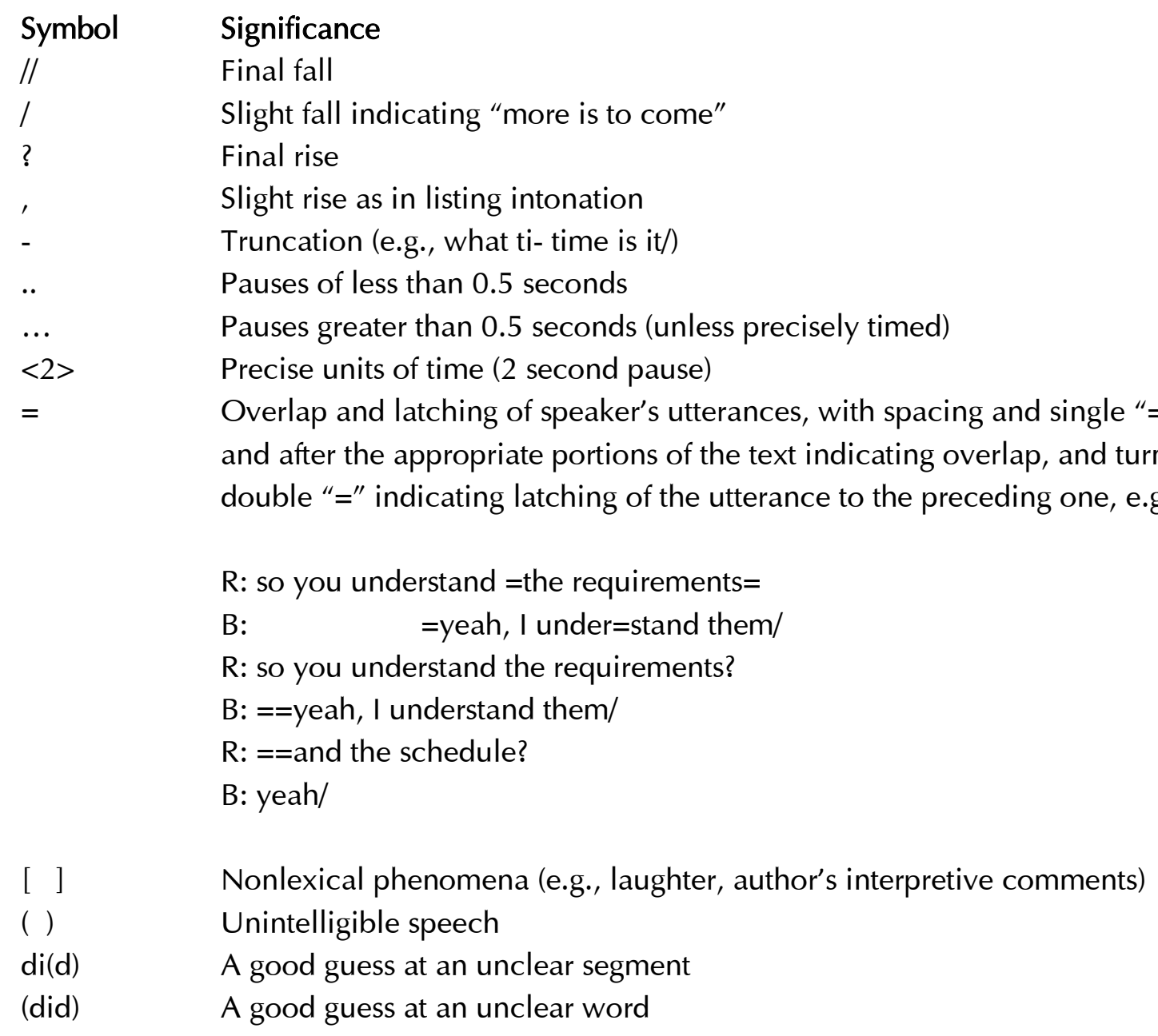

